\title{
Parent and PreService Teacher Partnering in a Technology-Based Home Intervention: Preliminary Findings
}

\author{
Wendi Beamish $^{1, a}$, Denis Meadows ${ }^{1, b}$, Matthew Prime ${ }^{1, c}$, Belinda Fisher ${ }^{2, d}$ \\ ${ }^{1}$ School of Education and Professional Studies, Griffith University, Brisbane, Australia; \\ ${ }^{2}$ CHI.L.D. Association, 33 Stoneham St, Stones Corner, 4120, Australia. \\ aw.beamish@griffith.edu.au, bd.meadows@griffith.edu.au, cmatthew.prime@griffithuni.edu.au \\ dbelinda.fisher@childassoc.org.au
}

\begin{abstract}
Keywords: iPad, apps, parent perspectives, preservice teachers, autism spectrum disorder, communication impairment
\end{abstract}

\begin{abstract}
This small-scale Australian study employed a mixed method design to explore the perspectives of parents and preservice teachers who worked together on a technology-based home intervention to better engage children aged 4-5 years with communication difficulties in the family morning routine. A mini-iPad was used by each parent to support their child's learning of self-care skills, and parents were individually coached on the technical and pedagogical aspects of the intervention by preservice teachers. Preliminary results from parent interviews, preservice teacher weekly reflections, and parent and preservice teacher online surveys provided strong support for the use of the iPad as a promising tool for interventions of this kind.
\end{abstract}

\section{Introduction}

Beginning special educators need to be workplace ready on graduation. These circumstances demand that they not only have the pedagogical knowledge but the professional experience across a broad range of practice, including digital technologies and working with families. The use of digital technology to boost learning outcomes for students with diverse needs has been well documented [1]. More recently, findings from iPad use at home and at school by children with disabilities, particularly those on the autism spectrum, has yielded positive outcomes [2, 3, 4, 5]. For these reasons, Griffith University special education staff collaborated with an industry partner, CHI.L.D Association (Let's Talk Developmental Hub, http://www.letstalk.org.au/child-assoc.html) in Brisbane Australia to apply for nongovernment funding through Ian Potter Foundation (http://www.ianpotter.org.au/) to undertake a home-based intervention study in which preservice teachers partnered with families of young children with communication difficulties.

Many young children with communication difficulties are unable to use language to share information about their needs, wishes, and concerns and typically have a poor understanding of what others say. Without intervention, these children face a host of problems, including a limited capacity to express emotions and the development of inappropriate behaviours, which in turn set a developmental trajectory for emotional problems across childhood [6]. In the preliminary planning phase, university and Let's Talk staff sent a Needs Assessment survey to all families with underschool-age children attending CHI.L.D's outreach clinic. The majority of responding parents (60\%) identified the morning routine as an area of difficulty for their child and family. This result is not surprising because communication demands at this busy time of the day are typically high for all families. However, these parents, in addition to attending to the usual responsibilities, need to not only tell their child what to do so that the message is understood but also engage their child in completing self-care tasks within the routine (e.g., eating breakfast; getting dressed).

Previous studies provided evidence that technology capable of providing pictorial prompts was effective in promoting independence, reducing the quantity of adult prompts, and improving transitions between activities for children with disabilities [7]. The research team, therefore decided to pilot an approach using the iPad and an app to engage and motivate these young children to learn self-care skills through visual displays rather than through direct verbal prompting by parents. 
The Choiceworks app by BeeVisual (http://www.beevisual.com/) was selected because of its easy-to-use format and picture-based design specifically for daily routines. Funding made it possible for a mini-iPad and Choiceworks app to be purchased for use by each participating family. Further, parents were to be individually coached on the technical and pedagogical aspects of supporting their child's learning within the context of the home-based intervention by preservice teachers.

Four research questions framed the project. The first two were related to parental perceptions and satisfaction with the overall intervention and in using the iPad as a teaching tool. The final two were related to the professional learnings gained by preservice teachers through engagement with parents in the intervention. This paper will restrict reporting to parent and preservice teacher perspectives on the use of the iPad as a teaching tool within the context of the home-based intervention during the family morning routine.

\section{Method}

Participants. Altogether, 13 families and an equal number of preservice teachers took part in the study. Participating family members were 12 mothers and a grandfather with an age range from 25 to $50+$ years. These participants will be referred to as parents hereafter. Children were aged 4-5 years, with approximately $50 \%$ of the group having a diagnosis of autism spectrum disorder. The preservice teachers were predominately female (85\%), aged between 20 and 45 years, and were completing their final year in the Bachelor of Education (Special Education) at Griffith University.

Research design and data collection procedures and analysis. The study was conducted in three phases using a mixed method approach: pre-intervention data gathering (Week 1), intervention with data gathering (Weeks 2-10), and post-intervention data gathering (Week 16). Data collection tools included pre-intervention and end-of-intervention parent interviews, weekly reflections by preservice teacher during intervention, and final online surveys for preservice teachers and parents. The quantitative data collected from these sources were subjected to simple descriptive analysis, with the number of response categories on the 5-point Likert scales decreased to three using a data collapsing strategy [8]. Qualitative data were subjected to a thematic analysis to generate patterns and consistencies of meaning that identified themes and categories [9].

\section{Results}

Parent perspectives. Participating parents were interviewed on two occasions, prior to the intervention (Interview 1) and immediately after the intervention concluded (Interview 2). Parents also participated in an online survey 1 month post-intervention (follow-up). During Interview 1, parents were asked if the family used a tablet device of any kind within the home. Eight parents (62\%) reported owning an $\mathrm{iPad}$, and predominately using the device with their child to play therapy games. They were also asked to rate their level of satisfaction with their child's pre-intervention participation in the morning routine. Eleven parents $(85 \%)$ expressed dissatisfaction while two $(15 \%)$ were satisfied. Eight parents participated in Interview 2, with two indicating that they were satisfied with their child's current level of participation, while 6 were more than satisfied. Comments included: "He understands better what has to be done," Nowhere near as stressful now," "Don't have to do the repetition and nagging," and "Overall, a big improvement."

In the online survey a month later, these eight parents confirmed similar levels of satisfaction with their child's improvements. They were also asked to rate and comment on particular aspects of iPad use. Table 1 presents survey questions with corresponding ratings. High ratings were given to the likelihood that parents would use an iPad for instructional purposes with their child in the future and that they would recommend iPad use to other parents. Ratings for the likelihood that they would recommend iPad use to their child's teacher were also high. Overall, parent satisfaction about the manner in which their child participated and improved in the morning routine as a result of the iPad instruction was rated highly, as were questions relating to their future iPad use. 
Table 1. Parent Ratings for Questions Associated with iPad Use in the Online Survey

\begin{tabular}{|c|c|c|c|}
\hline Question & \multicolumn{3}{|c|}{ Rating Continuum } \\
\hline Overall, how satisfied are you with: & Not satisfied & Satisfied & More than satisfied \\
\hline $\begin{array}{l}\text { your child's present participation in the } \\
\text { morning routine? }\end{array}$ & 0 & 2 & $\begin{array}{c}6 \\
(75 \%)\end{array}$ \\
\hline $\begin{array}{l}\text { using an iPad to teach your child aspects } \\
\text { of the morning routine? }\end{array}$ & 0 & 4 & $\begin{array}{c}4 \\
(50 \%)\end{array}$ \\
\hline How likely is it that you would: & Unlikely & Likely & More than likely \\
\hline $\begin{array}{l}\text { use an iPad in the future to teach your } \\
\text { child to do things at home? }\end{array}$ & 1 & 3 & $\begin{array}{c}4 \\
(50 \%)\end{array}$ \\
\hline $\begin{array}{l}\text { suggest to your child's teacher using an } \\
\text { iPad with your child? }\end{array}$ & 1 & 2 & $\begin{array}{c}5 \\
(62.5 \%)\end{array}$ \\
\hline $\begin{array}{l}\text { suggest to other parents using an iPad } \\
\text { with their child? }\end{array}$ & 0 & 2 & $\begin{array}{c}6 \\
(75 \%)\end{array}$ \\
\hline
\end{tabular}

Preservice teacher perspectives. Preservice teachers documented weekly reflections of their experiences with parents across the intervention and completed an online survey at the completion of intervention period. These data were not based on their actual observations of children using the iPad to complete morning activities at home. Rather their reflections and responses were based on perspectives that parents had shared with them in an ongoing manner through email or phone contact across a 10 -week period.

Analysis of weekly reflections in this topic area revealed two main themes, one related to the positive aspects of iPad use and another related to challenges. Under both of these major themes, a number of sub-themes emerged (see Table 2).

Table 2. Key Themes with Definitions in Preservice Teachers' Reflections on iPad Use

\begin{tabular}{lc}
\hline Themes concerning positive aspects of iPad use & Themes concerning challenging aspects of iPad use \\
\hline $\begin{array}{l}\text { Motivating/stimulating/engaging } \\
\text { refers to the enthusiasm and focus with which the } \\
\text { children approached the task using the iPad. }\end{array}$ & $\begin{array}{c}\text { iPad as a game-only device } \\
\text { refers to the children having to adjust to the } \\
\text { iPad being used for purposes other than the } \\
\text { playing of games and that game use was } \\
\text { contingent on using the iPad to complete } \\
\text { morning activities. }\end{array}$ \\
$\begin{array}{l}\text { Ease of use } \\
\text { refers to trouble free manner in which the visual display } \\
\text { on iPad could be integrated into the learning experience } \\
\text { during morning activities. }\end{array}$ & $\begin{array}{c}\text { Parent facilitation } \\
\text { refers to parents realising that the iPad alone } \\
\text { cannot facilitate improvement and that they } \\
\text { must be proactive in supporting their child's } \\
\text { refers to the speed of acquisition with which children } \\
\text { learnt to complete morning activities. }\end{array}$ \\
$\begin{array}{l}\text { Games as rewards } \\
\text { refers to the motivating effect that access to games } \\
\text { provided as a consequence for using the iPad to complete } \\
\text { morning activities. }\end{array}$ \\
$\begin{array}{l}\text { Value as a learning tool } \\
\text { refers to the worth parents placed on using the iPad to } \\
\text { teach children a variety of tasks at home. }\end{array}$
\end{tabular}

On the one hand, preservice teachers recounted parent accounts about children finding the iPad to be a motivating, stimulating, and engaging gadget. In addition, they reported that most parents needed little technical coaching as they found both the iPad and app easy to use as a support with their children during the busy morning routine. As a consequence, this intervention approach led to most of the children making progress with the morning routine, a view reflected by the parent data cited previously. The strategy of using game applications as a reward for completing the morning routine activity was reinforcing for the children and motivated them to engage with the routine activity on future occasions. Overall, preservice teachers provided rich commentary about the value of using iPads as an instructional tool in home interventions. On the other hand, preservice teachers reported that parents encountered some iPad-related challenges. Some children with prior history of using iPads as a game-only device had to adjust to the idea that the games were a reward contingent on participating in the self-care activity. Further, some parents thought that the technology alone 
would facilitate learning for the child, but it became apparent in the first few days that they had to facilitate their child's learning with instruction and support. Finally, an older parent shared that he found the technology challenging and required numerous coaching sessions to address this issue.

In the online survey, preservice teachers rated their experience using an iPad as an instructional tool by answering the question How likely would it be that you will use iPads in your class next year? Together they assigned a high rating of 4.5 on a 5-point Likert scale, indicating that they endorsed the use of this device for instructional purposes. They were also asked to reflect on what they had learnt in relation to the iPad as a learning tool. Typical responses were: "a very comprehensive learning tool with a vast range of uses that can be adapted to an individual's needs," "versatility! You can edit, adapt, personalise every feature of the visual schedule," "a good motivational tool," "children gravitate towards them," and "iPads are socially acceptable. Students can walk around with an iPad visual schedule and no one in the school or community would stop and stare."

\section{Summary}

Overall, this study builds on existing research that supports iPads as a promising tool for intervention with young children with disabilities. Findings showed that parents, even during one of the busiest times of the day, could effectively use the device as a support to engage their children in completing self-care tasks. Moreover, if parent reports about their children's increased competence and confidence in using the iPad are correct, these youngsters are not only experiencing a better start to the day, but hopefully a better start when they begin school.

\section{References}

[1] R. Croser, Inclusive technology, in: A. Ashman (Ed.), Education for Inclusion and Diversity, Pearson Australia, Melbourne, 2015.

[2] R.M. Dixon, I, Verenikina, D. Costley, and S, Pryor, The use of iPads in the home settings for students with autism spectrum disorders, Journal of Special Education Technology. 30 (2015) 193-206. doi:10.1177/0162643415623023

[3] M.L. Clarke, D.W. Austin, and M.J. Craike, Professional and parental attitudes toward iPad application use in autism spectrum disorder, Focus on Autism and Other Developmental Disabilities. 30 (2015) 174-181. doi:10.1177/1088357614537353

[4] D.M. Kagohara, L. van der Meer, S. Ramdoss, et al. Using iPod and iPads in teaching progarms for individuals with developmental disabilities: A systmatic review, Research in Developmental Disabilities. 34 (2013) 147-156. http://dx.doi.org/10.1016/j.ridd.2012.07.027

[5] J. Vandermeer, W. Beamish, T. Milford, and W. Lang, iPad-presented social stories for young children with autism, Developmental Neurorehabilitation. 18 (2015) 75-81. doi:10.3109/17518423.2013.809811

[6] S. Goh, K. Yew, and R. O'Kearney, Early language impairments and developmental pathways of emotional problems across childhood, Int J Lang Commun Disord online. (2014) 1-16. doi:10.1111/1460-6984.12142

[7] G. Hayes, S. Hirano, G. Marcu, et al. Interactive visual supports for children with autism, Personal and Ubiquitous Computing. 14 (2010) 663-680. doi:10.1007/s00779-010-0294-8

[8] W. Beamish, Consensus about Program Quality: An Australian Study in Early Childhood Special Education, VDM Publishers, Saarbrucken, Germany, 2008.

[9] V. Braun, V. Clarke, Using thematic analysis in psychology, Qualitative Research in Psychology. 3 (2006) 77-101. doi:10.1191/1478088706 qp063oa 